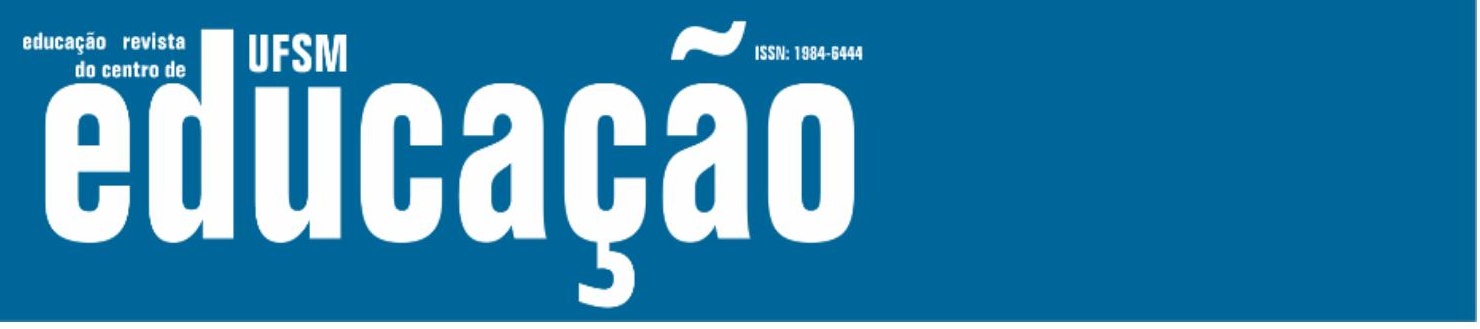

ISSN: 1984-6444 | http://dx.doi.org/10.5902/1984644440241

\title{
Os tempos da ação docente na classe hospitalar
}

\author{
Teaching times in hospital classroom
}

\author{
Angélica Macedo Lozano Lima \\ Professora doutora na Secretaria de Estado da Educação, Curitiba, Paraná, Brasil. \\ gelylozano@gmail.com - https://orcid.org/0000-0002-4317-556X \\ Rosario Silvana Genta Lugli \\ Professora doutora na Universidade Federal de São Paulo, São Paulo, Brasil. \\ gentalugli@gmail.com - https://orcid.org/0000-0001-7893-8646
}

Recebido em 29 de setembro de 2019

Aprovado em 27 de janeiro de 2020

Publicado em 20 de março de 2020

\section{RESUMO}

Partindo das referências temporais presentes em entrevistas realizadas com professoras de classe hospitalar em três instituições de Curitiba, bem como em observações in loci das práticas, discute-se o choque entre a duração real das aulas e a duração burocraticamente exigida pelas autoridades escolares, com suas consequências sobre $o$ trabalho. Os principais conceitos mobilizados referem-se ao território, como forma de estruturação hierárquica do espaço, e, ao lugar, como construção de um modo de pertencimento marcado pela afetividade. Desse ponto de vista, assiste-se a um processo de desterritorialização num sentido amplo, abrangendo ainda as práticas escolares no hospital, ou seja, estas acontecem num ambiente que não está estruturado em função do ensino, portanto, a classe hospitalar aparece como um fenômeno de reconstrução e ressignificação das práticas socialmente determinadas em cada evento de ensino-aprendizagem, cujas marcas mais evidentes são a individualização e a afetividade. Como expressão desse processo, predominantemente aflora a criatividade das professoras, circunscrita pela territorialidade e temporalidade do hospital, suas regras e hierarquias ${ }^{1}$.

Palavras-chave: Classe hospitalar e ensino; Lugar e território; Temporalidade.

\section{ABSTRACT}

Based on the temporal references present in interviews with hospital-class teachers in 3 institutions of Curitiba, as well as on observations in loci of the practices, we discuss the clash between the actual duration of the classes and the bureaucratic duration required by the school authorities, with their consequences on work. The main concepts mobilized refer to territory, as a form of hierarchical structuring of space and to place, as the construction of a mode of belonging marked by affectivity. From this 


\section{Fism \\ ISSN: 1984-6444

ISSN: 1984-6444 | http://dx.doi.org/10.5902/1984644440241

point of view, there is a process of deterritorialization of the school practices in the hospital, that is, they take place in an environment that is not structured according to teaching and, therefore, the hospital class appears as a phenomenon of reconstruction of social practices that arise in each teaching-learning event, whose most evident marks are individualization and affectivity. As expression of this process, the creativity of the teachers, circumscribed by the territoriality of the hospital (its rules and hierarchies) appear predominantly.

Keywords: Hospital-class and teaching practices; Place and territory; Temporalities.

\section{Introdução}

Apresentam-se alguns resultados de uma pesquisa de doutoramento "Classe hospitalar: do território ao lugar em tempos e espaços educacionais", sobre educação hospitalar, um espaço complexo e interdisciplinar. Os referenciais geográficos são os conceitos território e lugar, elencados para discutir a prática docente e suas potencialidades criativas quando transposta do território escolar institucionalizado, para outro, marcado pelas regras e práticas da instituição hospitalar. A questão central deste texto remete aos tempos do ensino: como são modificados pela situação de desterritorialização, como se reorganizam no novo ambiente e, finalmente, como essa modificação produz divergências entre o tempo vivido do ensino no hospital (que tem como horizonte a cura ou a morte) e o tempo regulado da instituição escolar.

Para essa discussão, dois espaços pesquisados (hospital e escola) foram tratados como territórios, pois, apresentam atributos inerentes ao conceito. Os aspectos espaciais e relacionais acontecem nestes espaços impregnados de elementos da territorialização: as relações de poder, políticas, simbólicas, identitárias e ainda relações correspondentes aos limites físicos ou abstratos que demarcam fronteiras e são apresentados simbolicamente ou materializados.

A desterritorialização, conceito emprestado de Deleuze e Guattari (2008), trata da espacialização das relações, referentes ao território escolar do qual as professoras saem, processo carregado de simbolismos, pois, os sujeitos deixam a segurança obtida por meio de longos períodos de experiências e repertórios passados. Deixar tudo o que é certo de lado para sair rumo ao desconhecido, é uma 


\section{OF LFH \\ 7 15SN: 1984-6444

ISSN: 1984-6444 | http://dx.doi.org/10.5902/1984644440241

viagem, rota que se percorre simultaneamente em dimensões espaciais e relacionais. Quando saímos de um espaço e vamos ao outro, levamos e deixamos coisas, e nesse deixar coisas, obtemos outras para ocupar o espaço daquilo que ficou para trás. Essa desterritorialização é, portanto, espacial e relacional, ao mesmo tempo. Ela retira conceitos e cria outros, retira modos e práticas e cria outros. E é neste movimento que podemos chamar de fluxo, que as professoras e os estudantes perdem e ganham.

Para entender tais fatos, foi retomada das referências do campo da educação, a ideia de forma escolar, tal como apresentada por (VINCENT et al, 2001) que remete a toda estrutura institucional que faz da escola um ambiente destinado exclusivamente ao ensino coletivo. Ao descolar-se do ambiente físico da escola, a forma escolar fragmenta-se para assim acompanhar as práticas docentes no hospital, que também flexionou seu território para recebê-las. Como territorialidade, no sentido temporal do termo, a classe hospitalar rompe com a forma escolar tradicional. É possível, desta forma, definir os termos e separar Educação Hospitalar de Classe hospitalar e compreendê-los assim: Educação Hospitalar é um termo adequado para conceituar uma modalidade da educação, um serviço educacional que atende estudantes internados em qualquer hospital. Classe Hospitalar é um termo adequado para a aula, que em ato, é o mais próximo da relação de temporalidade deste tipo de ensino, o encontro que acontece em determinados momentos, em determinados espaços, cedidos temporariamente para o serviço prestado pela Educação Hospitalar.

Já o ambiente tratado pelo conceito lugar é formado pela vivência, assim, lugar toma a forma de classe hospitalar criada no tempo-espaço da ação educativa. A classe é um ato de ensinar e aprender em proximidade, interação, sintonia, diferente de escola, de escolarização, a classe é um evento, um acontecimento entre tantos outros na rotina do paciente que o transforma novamente em aluno. Neste sentido, o território hospitalar e o tempo de ação, conspiram favoravelmente para que a relação professora-aluno que acontece no tempo da classe seja modificada pelas circunstâncias que incidem entre as rotinas da saúde no período de internação, no qual os dois sujeitos se veem impelidos a uma relação amistosa, propiciando uma interação de qualidade que culmina num desejo de estudar e aprender e ao mesmo tempo de ensinar. 


\section{F Fsm Ellthanáo}

ISSN: 1984-6444 | http://dx.doi.org/10.5902/1984644440241

\section{Aspectos metodológicos}

A reflexão neste artigo baseia-se nas informações coletadas em alguns hospitais em Curitiba que oferecem Educação Hospitalar pelo SAREH (Serviço de Atendimento à Rede de Escolarização Hospitalar). O Estado seleciona professoras e pedagogas concursadas e assegura uma estrutura administrativa e pedagógica que atende estudantes em tratamento de Saúde a partir do Ensino Fundamental II ao Ensino Médio.

Foram mais de 30 horas de observação de aulas e reuniões registradas em diário de campo em três hospitais. Essas observações têm como sujeitos, aluno e professora. Já as entrevistas foram feitas com professora ou pedagoga individualmente e outras coletivas com professoras, pedagogas e outros agentes da área da saúde, como enfermeiros, psicólogos, terapeutas, entre outros. Neste artigo escolheu-se apenas narrativas de professora, pedagoga e enfermeira. Entretanto, sujeitos e suas funções não podem ser identificados, conforme as regras das instituições ${ }^{2}$.

A natureza das fontes permitiu identificar o sentido de algumas práticas, que foram corroborados pelos entrevistados e, as entrevistas permitiram mapear a rede de significados atribuídos ao território e que circunscrevem a afetividade presente no lugar efêmero, uma classe hospitalar que surge ao se iniciar o tempo indeterminado da lição, subordinada aos fatores: vontade dos pais e do paciente, tipo de doença ou tratamento, condição de saúde; sensibilidade da enfermagem/médicos, diretrizes burocráticas. Uma miríade de elementos que a professora deve administrar imediatamente ao chegar ao leito que pode ser transformado, num passe de mágica, num lugar de ensino, fugindo completamente dos tempos da forma escolar da escola regular.

\section{O tempo na prática da classe hospitalar}

Como lugar criado em meio a um território hierarquizado e altamente controlado, a classe hospitalar caracteriza-se por sua efemeridade. Tudo pode se 


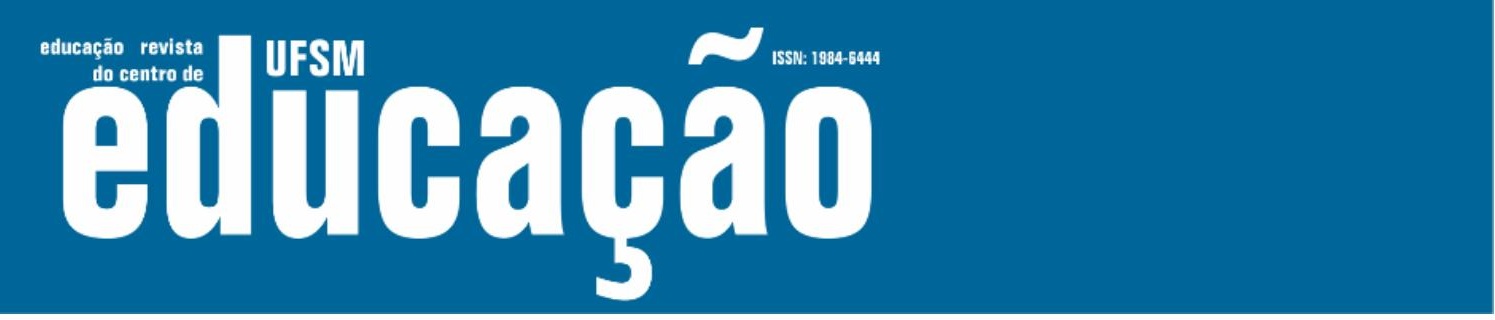

ISSN: 1984-6444 | http://dx.doi.org/10.5902/1984644440241

desmanchar: a aula, o espaço e o tempo escolar. No hospital, o caráter flexível dos tempos e espaços escolares "tendem a desfazer as formas [...] obedecendo a um esquema intuitivo" (CARDOSO JUNIOR, 2012, p. 602). O seguinte relato exemplifica o que se entende por fluxo:

Pesquisadora: você acha que faz diferença esse teu envolvimento bem perto da aula e da professora, você presente ali com o aluno e a professora e aquela aula acontecendo? Você acha importante? Pode atrapalhar? Qual a tua opinião?

Rosa: É relativo. Tem vezes que eu vejo que eu atrapalho, eu acabo entrando, invadindo o espaço do professor, e às vezes me incomoda. Eles não falam nada, lógico que não falam e, às vezes até peço desculpas. Eles dizem: "não tem problema". Mas, depende muito do atendimento. Às vezes acabo, [atrapalhando]. Esses dias até estava [professora] dando aula para o [aluno] e era aniversário dele, eu falei: "nossa, a gente tem aniversariante hoje, parabéns, [aluno]". Depois, eu falei assim: "inconveniente né?". Podia ter feito isso depois. Só que, foi tão espontâneo, eu olhei no quadrinho de aniversariantes, eu coloco uma "mensagenzinha" para eles, "[aluno] pra você". Aí ele leu: "nossa, obrigado, ninguém faz isso, que legal". Eu acabei atrapalhando a aula ali.

Pesquisadora: Mas você acha que esse tipo de ruído, vamos chamar de ruído, você acha que esse tipo de ação atrapalha?

Rosa: Então, depende, porque [a professora] levou numa boa. Ele acabou, absorvendo, mas, eu quebrei o raciocínio da [professora] entendeu? Da [professora] e também, do [aluno]. Eles estavam num ritmo ali, no conteúdo e o [aluno] ia responder uma questão [que a professora fez] e eu quebrei. (ROSA. Entrevista concedida em 14/09/2016, parágrafo 24).

Cardoso Junior mostra que "tudo acontece pelo meio, a aula agora é apenas um lugar de passagem para fluxos de toda ordem. Em uma aula também há sono, delírio e catatonia, visões e audições que nada têm a ver com o que o professor está falando" (CARDOSO JUNIOR, 2012, p. 602). Assim é no hospital, e, no entanto, no meio desta flexibilidade, os currículos e o cronograma temporal estão embasados nas escolas de origem e nas séries dos estudantes, são eles que orientam as etapas do dia de trabalho do professor hospitalar, por mais que ele queira se desvincular dos padrões impostos pela escola ao longo de um processo histórico, não há como negar a determinação da manutenção de seu modelo duro nestes espaços não escolares.

No hospital cria-se toda uma organização que tenta manter a ação das professoras sob a mesma formatação da escola regular (forma escolar), porém, não há o que fazer, sempre aparece um ponto de fuga; em tempos e espaços flexíveis, a subjetividade das ações exerce uma força maior, direcionada para a mudança da prática pedagógica delas e, o ponto de tensão se estabelece. Desta vez, em vez de 


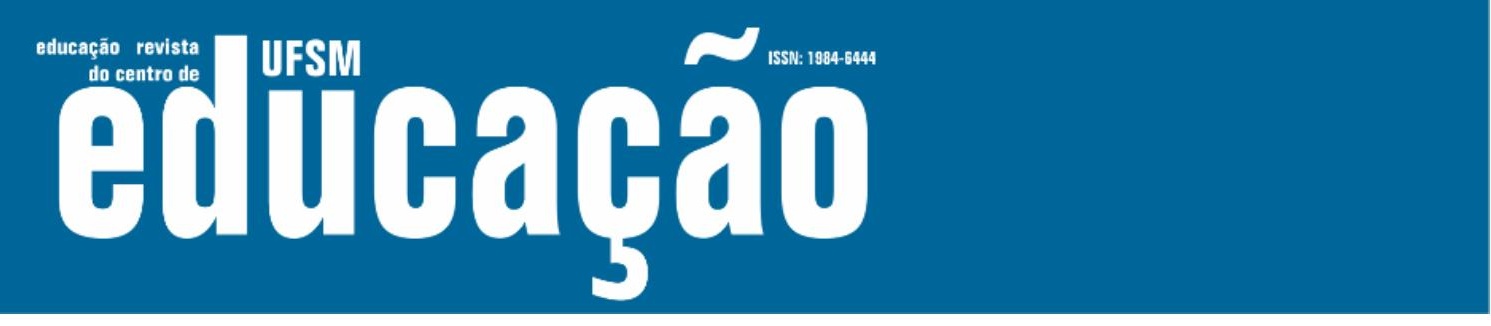

ISSN: 1984-6444 | http://dx.doi.org/10.5902/1984644440241

ser entre professora-aluno, o conflito geralmente se estabelece no nível professoraorganização institucional escolar que, neste caso, é representada pela figura da pedagoga, fato que representa uma surpresa para a investigação. Como registrado nas entrevistas, esta profissional investe maciçamente em ações disciplinares, normatizadoras, burocráticas, geralmente, idênticas às da escola regular. Tais condutas $^{3}$, conforme mostram as entrevistas, estão relacionadas ao modelo da sua formação, que atribui determinado perfil ao profissional, passa pelo distanciamento da rotina das professoras e suas práticas com alunos, pela falta de compreensão do verdadeiro sentido do fazer professoral neste ambiente, de modo suficiente que permita deixar-se transpassar pelo fluxo de flexibilidade e de mudanças nas ações habituais, mantendo-se inflexível na linha estriada da forma escolar, como se percebe a seguir:

Pesquisadora: Como você lida com o tempo no espaço hospitalar?

Camélia: O tempo? Não sei, não entendi direito. Do que você está falando? O tempo da aula, o tempo de que coisa, o tempo e o espaço?

Pesquisadora: Eu só posso fazer a pergunta, você tenta responder o que você compreende. (risos).

Camélia: (Risos) então, eu e o tempo, eu me organizo, eu tenho tantos alunos, eu organizo o tempo de acordo com o número de alunos que eu tenho, e de acordo com os que estiverem lá. Eu vou atender. Se a aula está rendendo bastante, se eu posso ficar uma hora, uma hora e meia eu fico. Eu ficava bastante tempo com a [nome], principalmente quando eu sabia que depois eu não teria outro aluno. Se tenho outros alunos, é outra coisa, reorganizo, fico uns 30, 40 minutos, se eu quero tomar um café, atendo três ou quatro antes, dois ou três depois. Eu lido bem tranquila com o tempo. $\mathrm{E}$ na escola você tem [diferença]. Eu senti muita dificuldade aqui porque a [pedagoga] queria assim, [nome] colocou inclusive o nosso horário, e ela colocou o horário de escola. Exige que marque horário de começo e fim. Então, eu falei para [...]: "[...] aqui não é escola. Esse horário é furado. Aqui você tem que lidar com o teu tempo de outra forma, você que faz o teu tempo". Então eu faço assim, eu faço meu tempo, eu não me ligo totalmente naquele horário que foi determinado. O que acontecia? Como alguns alunos estavam [em determinados lugares] e tinha horário marcado para atender, isso deu problema, três horas da tarde, precisava estar lá para atender, e se eu tinha alguém para atender antes, em outro lugar, eu precisava encerrar a aula antes das três, precisava organizar o horário para estar lá. [na hora marcada], (CAMÉLIA, entrevista, 2017).

Conforme o relato, as atividades preparadas para os estudantes internados devem considerar um tempo de aula mínimo de 20 a 30 minutos, e, além disso, porque devem ter começo, meio e fim, não podem passar para outro dia, apenas quando é um aluno de longo período de internação, existe a possibilidade de uma sequência. 


\section{OF LFH elllatä́}

ISSN: 1984-6444 | http://dx.doi.org/10.5902/1984644440241

Neste sentido, está implicado na atividade, um tempo aproximado, implícito, ou seja, ela é organizada para ser realizada neste tempo, portanto, a própria aula e seu aspecto metodológico retratam o tempo de realização, ratificando-o. Além disto, todo professor reconhece que um conteúdo na atividade individualizada pode ser trabalhado na metade do tempo que seria necessário na escola regular, às vezes, até menos.

O que ocorre quando o aluno-paciente está muito interessado: a professora pode realizar outras atividades, ou, estender a mesma atividade, enriquecendo a interação de modo que uma informação se relaciona com outras, ampliando o tema com a participação e questionamento do aluno e, às vezes, de quem está perto assistindo. A aula neste sentido, passa a ter outro tempo, é o tempo do encontro, sendo assim, ela é incompatível com um tempo cronometrado em minutos, como na escola. Cabe ressaltar alguns aspectos desta entrevista: cronometrar essa aula não passa de uma exigência burocrática, que chegou às várias classes hospitalares do SAREH, partindo de uma leitura extremamente rasa dos fundamentos deste tipo de educação e dos propósitos do programa; e ainda cria processos de trabalho que se desviam do verdadeiro objetivo da prática docente neste espaço, assim como das reais finalidades do serviço.

Sendo assim, é fundamental destacar que o serviço prestado pelas docentes do SAREH sempre prezou pela organização de atividades individualizadas, processos realmente importantes. Quando estes processos vão aos poucos sendo substituídos por um trabalho meramente burocratizado, utilizado para trâmites administrativos (papelocracia), a criatividade professoral perde forças, importante diferencial do trabalho, o que acarreta uma aproximação do atendimento à forma escolar da escola regular, descaracterizando o serviço.

O que se percebe é que as mudanças nas ações das professoras e dos alunos representam claramente a ruptura com a forma escolar. Porém, essa ruptura não é suficiente para que as mudanças possam atingir os outros agentes, permanecendo geralmente no plano da rotina da professora-aluno, que se flexibilizou para atender o estudante. No trecho da entrevista a seguir há outro exemplo: 


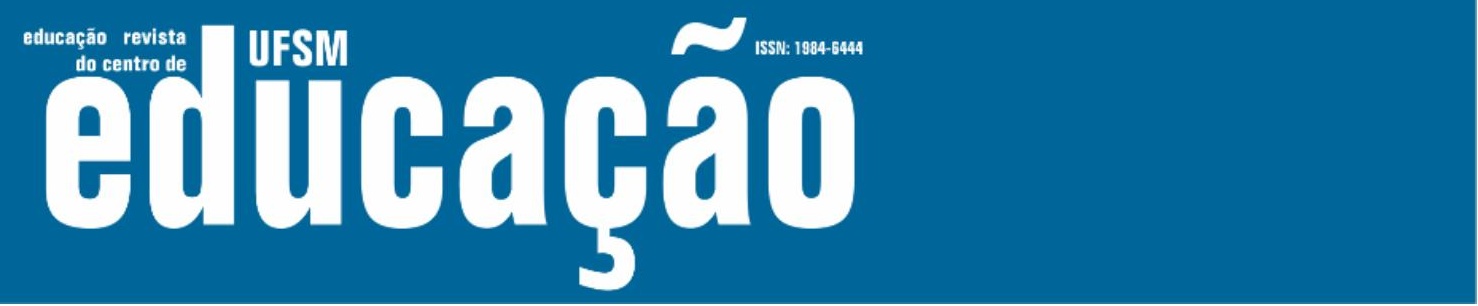

ISSN: 1984-6444 | http://dx.doi.org/10.5902/1984644440241

Pesquisadora: Como vocês elaboram a rotina de trabalho?

Begônia: A rotina, bem, geralmente no horário 13:10 até mais ou menos 16:00, temos os alunos, [muitos deles estão aqui porque tem o ônibus], eles chegam com o acesso vão embora com o acesso.

Pesquisadora: $O$ acesso é o ônibus?

Begônia: É [...]. Eles chegam 13:10, o [aluno] também vem sozinho, eles ficam no tempo deles, nós fazemos as atividades para eles e para o próximo dia, [geralmente] no período depois do lanche, até [um pouco] mais ou menos, e se não tiver nenhum aluno, porque antes, tínhamos alunos que chegavam nesse horário. Bem, nós vamos elaborar as atividades, que seriam nossas horas atividades, eu, particularmente, também elaboro em casa, eu simplesmente pego as atividades, porque eu não consigo concluir aqui, [levo] e na minha casa eu faço, e mais outras, mais atividades, no final da semana e no começo da semana eu já elaboro, [...] vemos qual é o plano de aula que a escola mandou, nós montamos esse plano [menor] daqui [...].

Pesquisadora: E você faz em casa por quê?

Begônia: A hora atividade não é suficiente e não é para a parte de estudo [...] ainda falta tempo. Na realidade, aqui a gente não conta tanto com a hora atividade, na realidade, às vezes, nós ficamos [com os alunos] as 5 aulas, [...], "agora nós vamos fazer a hora atividade", não, não temos. Normalmente é no final da tarde, após as 16:00, mas, às vezes quando tem aluno, não tem hora atividade, faz falta sim.

Pesquisadora: E você acha importante que tenha uma hora atividade regrada com horário, ou, do jeito que vocês organizaram aqui, na sua opinião é bom?

Begônia: Bom, assim, é que nós nos acostumamos, na realidade. [...] acredito que tenha que se ter mais tempo em termos de [horário de trabalho], [...] focar o objetivo que é SAREH, o estudo é aqui, precisamos estudar [ênfase]. (BEGÔNIA, entrevista, 2017).

Particularmente, o exemplo sobre a hora atividade 4 mostra a dificuldade de resguardar um horário de preparo e formação; há toda flexibilidade dos horários, porém, não existe dedicação exclusiva. Por outro lado, a hora atividade ainda é menosprezada por vários agentes e segmentos da própria área da educação, como tempo ocioso, improdutivo, ou seja, a hora para estudar e organizar o trabalho pedagógico não é encarada como parte dos afazeres profissionais, fundamental para exercer a profissão. Mantêm-se o discurso: "ao entrar no programa, as professoras conhecem as regras, sabem que se trabalha por áreas, têm mais trabalho, se não estão satisfeitas, podem desligar-se" (PROFESSORA, entrevista, 2016). Esta fala da entrevistada durante as conversas nas observações demonstra o tempo lento de Chronos, que se arrasta, dificulta geração de mudanças de atitudes, postura tal que impede a percepção do caráter diferencial que o SAREH concebeu nesses dez anos de existência. Esta expressão remete ainda ao espaço sólido: representa o espaço da 


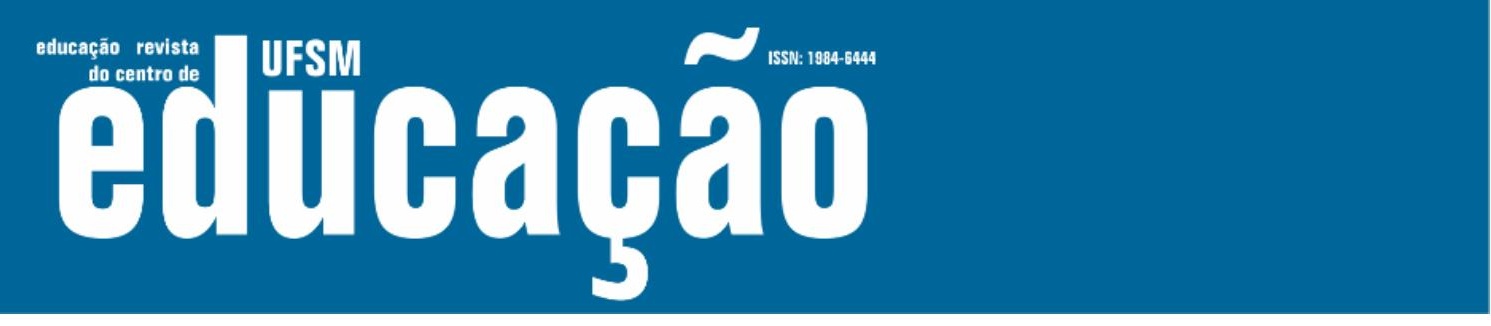

ISSN: 1984-6444 | http://dx.doi.org/10.5902/1984644440241

forma escolar da escola regular, impregnado nos discursos, nas atitudes; é naquele espaço "o lugar de normatização das subjetividades e moldagem de individualidades", não no SAREH, (CARDOSO JÚNIOR, 2012, p. 604). Entretanto, a criatividade prevalece quando as professoras encontram saídas, reorganizam os tempos e cumprem regras determinadas (ou não) pelas instâncias superiores.

Nos espaços e tempos abertos da classe hospitalar, rompe-se o modelo culturalmente conhecido; quando as professoras preparam atividades específicas, acompanham individualmente o aluno-paciente, seu desenvolvimento e evidenciam que quando ensinam (re) aprendem, recriam a relação professora-aluno, como no trecho a seguir:

Pesquisadora: O espaço faz diferença para alguma área disciplinar?

Acácia: para a educação física faz diferença sim, porque eu preciso de um movimento corporal e se eu não tiver um espaço adequado eu tenho que inventar várias atividades que possibilitem um movimento [...] se não tiver espaço eu tenho que criar uma forma.

Pesquisadora: E quando um aluno que só tem o movimento da cintura para cima, você trabalha apenas a parte teórica ou cria algo que seja possível fazer?

Acácia: Crio, [nome] teve aula de educação física, [...] que poderia fazer com ele além das aulas teóricas? Mostrar o esporte, [...] adaptado [...] o xadrez on line [...] ou, se não, eu fazia com que ele pudesse fazer os movimentos, do braço, [...] eu ajudava, [...] [ela mostra o movimento] ele conseguia fazer.

Pesquisadora: Com o dedo?

Acácia: Com o dedo, colocava o braço ali para ele, e aos poucos ele fazia o movimento ou ele apontava com cabeça, a peça que ele queira que eu mexesse e eu mexia para ele. Outro esporte eu trabalhei, além da frequência cardíaca, e o movimento que ele fazia, a parte de alongamento, só que tem que ajudá-lo, a esposa dele fazia um alongamento para ele, poderia fazer saindo da cadeira. Outra atividade foi a bocha adaptada, tínhamos aqui o capacete, mas, mesmo assim, ele queria tentar movimentar-se, então, ele pegava o braço, levantava um pouco naquele cano que tinha, ele tentava movimentar, colocava a bola, e quando eu via que ele ia movimentar-se, eu deixava posicionada a bola certinho, ele só tocava o dedo e a bola ia, era uma forma de movimento de educação física, não fiz mais porque acabou o tempo em termos de carga horária, mas se eu tivesse que trabalhar o ano todo, com certeza criaria mais coisas para ele. E agora em artes estou testando uma forma de assoprar, para quem tem a respiração invertida, [aluno] este, [por exemplo] não consegue sugar uma água por exemplo, não puxa no canudinho, eu estou tentando criar, para ajudar a fonoaudióloga, para ele fazer um movimento de assoprar.

Pesquisadora: E vai trabalhar o que? Vai soprar como?

Acácia: Arte rupestre, que eu já trabalhei [teórica] mas, eu quero que ele faça a prática. Então, eu comprei a tinta testei, não senti resultado, mas, ele não fez ainda a atividade de assoprar a tinta, então eu vou explicar como utilizar no canudo, ele vai colocar um pó e ele vai soprar, mas o sopro dele é muito

Educação | Santa Maria | v. 45 |2020

Disponível em: https://periodicos.ufsm.br/reveducacao 


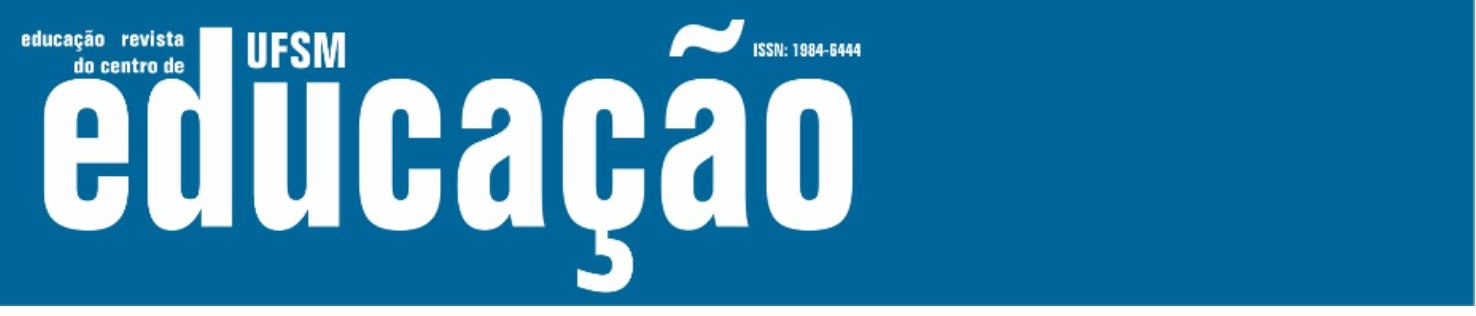

ISSN: 1984-6444 | http://dx.doi.org/10.5902/1984644440241

fraco, então eu tenho que ver como ele pode fazer para soprar adequadamente. $E$ antes, eu tinha o [aluno] que faleceu [...] não tinha o movimento, então na educação física, ele queria fazer esse movimento e precisava de espaço, nós jogamos xadrez. Ele ia nas peças e tentava movimentar, derrubava tudo, mas, colocávamos tudo de novo, ele fazia novamente, para ele o espaço teria que ser um espaço grande, materiais grandes, porque ele queria se movimentar, mas, ele não tinha coordenação motora suficiente, ele era um pouquinho diferente do [outro aluno].

Pesquisadora: E quando faz essas atividades, você percebe a diferença na expressão, como eles reagem?

Acácia: Ah sim, isso que me dá mais satisfação e eu gosto de ver, por isso que eu acho que eu crio mais coisas ainda, porque eles olham com aquele olhar de que estão gostando da atividade, isso que vale a pena você fazer. Até [aluno] ele está começando a falar, mas, ele fala muito baixo. O [aluno] quando começou a falar, estávamos com aula de inglês, eu falo "hello e você fala hi", ele olhava, ele tinha que virar a cabeça assim, porque tinha uma visão [baixa], ele olhava pra mim, quando ele via que era eu [chegando] ele já falava "hi" aquela forma dele falar, eu respondia, "ah hello [aluno]", ele já sabia o que tinha que responder, isso é emoção, isso é a forma, você percebeu que teve interação do aluno, e isso que me faz cada vez mais gostar do SAREH (ACÁCIA, entrevista, 2017).

Neste trecho está claro o caráter da humanização aliado à prática, que preza o diálogo e a interação. O conhecimento do outro e das suas necessidades deve ser valorizado na classe hospitalar, a humanização passa pelo fato de enxergar todos os aspectos da prática: os tempos e os espaços, que são permeados pelas relações subjetivas e pessoais, até a humanização do próprio trabalho. As ações, os espaços, os procedimentos e os fluxos hospitalares requerem esse exercício, e se essa metamorfose não alcançar todos os sujeitos envolvidos na equipe da educação hospitalar o processo desta aula fica prejudicado. A ação disruptiva da professora é o que permite o sucesso; a vontade do aluno-paciente estar ali, cria na professora outra experiência, estabelece uma mudança que se percebe quando se compara classe hospitalar com escola regular. A seguir, Margarida narra experiência que recria sua prática:

Pesquisadora: Com essas e experiências que você adquiriu no SAREH, tem alguma estratégia, metodologia que pudesse auxiliar ou melhorar o trabalho do professor na escola regular?

Margarida: A forma como eu trabalhei, por exemplo, a parte [da disciplina] não fiz assim: "- olha [aluna] vamos fazer atividade, questionário, não, não fiz isso!". Eu trabalhei muito com livros, com a leitura. E eu usei o celular e a Internet. Ela lia no livro eu combinava com ela assim: - você lê e o que você tiver dúvida, o que você quiser comentar, vai me falar, a gente vai fazer a pesquisa, procurar imagens etc. Eu trabalhei assim com ela, ela não ficou respondendo perguntinhas. Então, ela estudou bem o conteúdo, e depois a gente estudou juntas a parte que ela já tinha lido e visto no livro. A gente fazia

Educação | Santa Maria | v. 45 |2020

Disponível em: https://periodicos.ufsm.br/reveducacao 


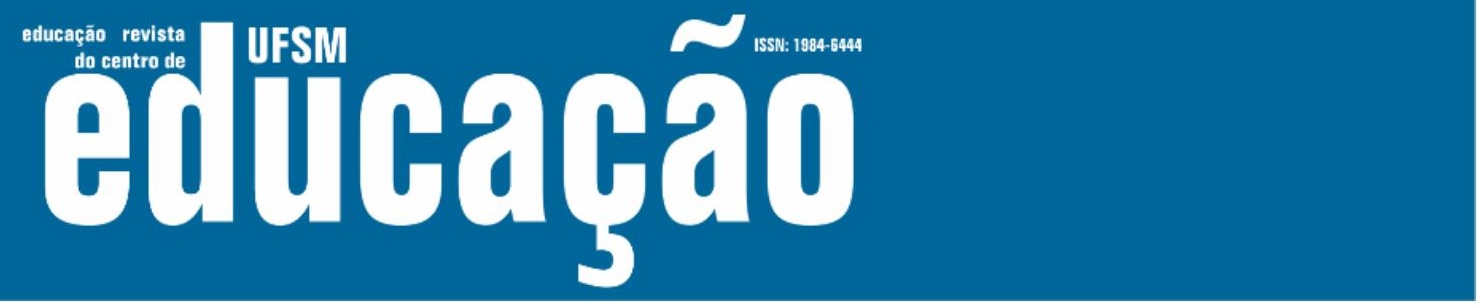

ISSN: 1984-6444 | http://dx.doi.org/10.5902/1984644440241

desta forma. Discutindo, e ela falava: "- nossa, eu não sabia que isso existia, que legal isso, que legal aquilo". Tanta coisa que ela descobriu, lendo nos livros. E ela falou que estava interessada em ler por causa da doença da bebê. Ela falou assim: "- eu tô entendendo melhor o que é que se passa com a nenê" (MARGARIDA. Entrevista concedida em 30/11/2016, parágrafo 303).

$\mathrm{O}$ ato de ensinar e aprender (estudar) totalmente relacionado ao contexto da realidade desta aluna, que tenta identificar no conteúdo escolar, o significado para o mundo real, é a função da escola. A diferença que se manifesta neste tipo de aprendizado, aponta que o interesse em aprender, nasce muitas no reconhecimento de que é necessário "algo" a mais para compreender a realidade em que se vive e atuar sobre ela, a escola deve ser capaz de proporcionar esse conhecimento. Esta mãe adolescente encontra nos estudos bases informativas para lidar com a doença da filha que a incentiva estudar. Isto foge do conteúdo curricular? Muito provavelmente não, pode ser um conteúdo organizado para outra série, bimestre, outro tempo escolar, porém, a forma de contextualizar este conteúdo, no tempo em que ele é necessário, foge do planejamento inicial, que é reconfigurado pela professora para esta situação problema, usando metodologias simples: livros, celular, um problema real, interação e afetividade. Bromélia mostra mudanças para atuar no hospital:

Pesquisadora: Você percebeu mudanças na sua forma de agir como professora nesse espaço hospitalar?

Bromélia: Ah, tem que mudar totalmente. Tem que se readaptar.

Pesquisadora: O que você pode contar, o que você percebeu e que já mudou?

Bromélia: Ah, a primeira coisa que a gente tem que mudar é a estruturação dos conteúdos. Então, não dá para [trabalhar] aquele conteúdo [suspiro] que a escola, nossa escola [ênfase] é conteudista [...] conteúdos que você tem que dar conta naquele período, para aqueles alunos. Aqui não. Aqui você não tem que ir pela quantidade, você tem que ir pela qualidade. Você tem que ir no tempo do aluno. É o tempo dele, se ele aprender um a um, se ele aprender dois a dois, se ele aprender três a três, mas, também, não é fragmentação, mas, tem que tornar ele [o conteúdo] mais fácil, quando a cognição dele está prejudicada, tem que trazer de uma maneira mais maleável para o aluno.

Pesquisadora: Você acha que isso é uma flexibilização ou uma adaptação? Bromélia: Acho que são as duas. Em determinado momento você tem que adaptar, a hora que você está adaptando, você está flexibilizando, porque não existe flexibilização sem adaptação. Do meu ponto de vista, mas eu acho que ocorrem as duas coisas: flexibilização e adaptação.

Pesquisadora: E sem essas duas características seria impossível trabalhar com esses alunos?

Bromélia: Ah, eles não dão conta. $E$, assim, do meu ponto de vista eu acho que é impossível ... é difícil a gente dizer. Mas, até pelo tempo que você fica com ele, o tempo que ele fica com você, é muito rápido, não dá para começar 


\section{工 WusM \\ ISSN: 1984-6444

ISSN: 1984-6444 | http://dx.doi.org/10.5902/1984644440241

uma aula hoje e terminar a semana que vem. Tem que começar, terminar hoje, avaliar hoje, pronto. Porque amanhã você não sabe se ele vai estar ali [sic] (BROMÉLIA. Entrevista concedida em 09/11/2016, parágrafo 57).

Além de fazer mudanças na prática, Bromélia se vê diante de outro elemento: um estudante interessado. Está atrelado ao modo de ensinar na classe hospitalar e no fluxo do aprendizado deste aluno a descoberta pelo interesse. Desde esclarecer curiosidades ou significados de termos até aprofundar-se em determinado assunto conforme a necessidade. Isto implica em liberdade. O currículo deve proporcionar essa liberdade e as instituições devem validar esse aprendizado.

Nem sempre a prova, pesquisa ou a lista de exercícios vindos da escola podem ser aplicados integralmente. Muitas vezes, o aluno avançou mais quando quis saber o significado daquela palavra desconhecida (na sala de aula provavelmente permaneceria desconhecida), ou quando escutou a canção sobre placas tectônicas e continentes (em inglês) mas, na aula de Geografia, e desejou conhecer a tradução da canção. Esse aprendizado segue as orientações do currículo em outra temporalidade e formato interdisciplinar. Entretanto, muitas vezes, o modo de controle do que ensinar ou como ensinar, próprio às formas da escola regular, que perpassa pelas duas formas, escola e classe hospitalar, limita o movimento da professora.

A flexibilidade começa desde a forma de elaborar atividades adequadas ao aluno, "independente do que a escola envia e acredita ser o apropriado", transcorre pelo tempo e finaliza com a redação do parecer descritivo, (no qual a professora atesta o quanto o aluno avançou). O professor no hospital precisa referenciar a sua experiência com o aluno de forma técnica, descritiva e objetiva, daquilo que foi conquistado pelo/com o aluno, (porque irá para a escola regular, lá onde está impregnada da forma escolar). A linguagem deve ser clara para aquele professor que recebe o parecer, porque se julga que a escola de origem não seja ainda capaz de compreender outra forma de avaliar, a não ser, mostrar que ocorreu o aprendizado com uma nota numérica; por isso, o parecer deve deixar "transparecer" uma nota. Porém, deve-se buscar constantemente o entendimento das práticas do SAREH, até que se mude para não exigir essa métrica. 


\section{Wusm \\ ISSN: 1984-6444

ISSN: 1984-6444 | http://dx.doi.org/10.5902/1984644440241

O que 0 aluno-paciente ganha na classe hospitalar: qualidade na aprendizagem, conteúdo significado e inter-relacionado no tempo do encontro. O que esta aula representa é muito mais que minutos, e estes, não expressam a qualidade dela ou do aprendizado, e sim representam uma estratégia simbólica para controlar o trabalho.

Neste sentido, a condição de fragilidade e vulnerabilidade do aluno-paciente é um dos fundamentos dos tempos das atividades, avaliações e do parecer. Não se pode avaliar o aluno-paciente, com base em argumentos como preguiça, falta de vontade, ou motivação, (como se faz na escola regular). Deixar de lado essa forma de observar e avaliar o aluno é essencial. Dizer que o aluno demonstrou enfrentamento, preguiça ou resistência às atividades sabendo-se que, em estado frágil da doença, não quis participar de algumas aulas (dependendo da sua condição de saúde, do estado psicológico depressivo) é outra comparação grotesca com a forma dura da escola regular. A rotina escolar hospitalar, não é, nem pode ser, de forma alguma imposta, ela é simplesmente aceita, outra diferença fundamental.

Quando o estudante começa a recusar as aulas da classe hospitalar, pode ser um indicativo de forte e maciça presença das características da forma escolar da escola regular interferindo nas ações da classe hospitalar. Nestes casos, entra o papel da equipe ao fazer o contato com os outros profissionais da saúde, o que pode ter grande peso para que este quadro de desmotivação seja minimizado e o desejo de estudar permaneça, sendo também fator para autorreflexão a respeito das próprias práticas, das atividades e do tipo de abordagem que se faz com este aluno-paciente ao apresentar a classe ou marcar os próximos atendimentos.

Perante várias entrevistas, transpareceu que, nos processos gerais, buscamse atrelar o tempo da escolarização hospitalar ao calendário do ano letivo regular, mesmo reconhecendo que o ano letivo do aluno-paciente é diferenciado da escola regular. Aliado a isso, permanecem dúvidas ou resistências sobre o processo escolar ocorrido durante a internação, já que só se reconhece aquele institucionalizado que incide na própria escola.

Neste cenário, buscam-se formas de respaldar documentalmente e justificar numericamente as ações das professoras, fundamentando ainda a burocratização do 


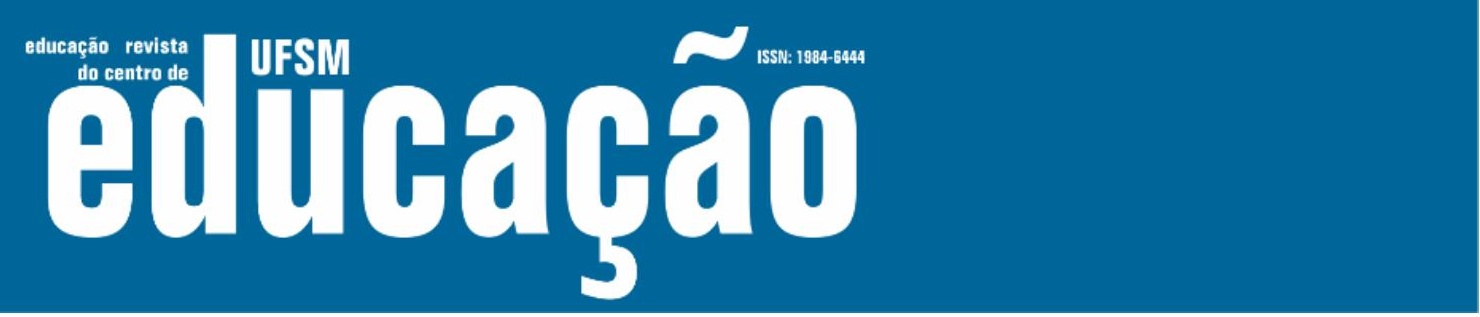

ISSN: 1984-6444 | http://dx.doi.org/10.5902/1984644440241

serviço. Neste sentido, a qualidade do material didático e a qualidade do contato, (elementos fundamentais da análise), perdem a relevância, já que, é o próprio material e a ação temporal implícita nele que se configura como moderador do tempo da aula e sua qualidade. Ao valorizar o tempo cronometrado, se desvaloriza a importância do encontro. É fundamental manter dados estatísticos dos atendimentos, porém, isso não justifica confundir tempo escolar hospitalar com tempo da forma escolar da escola regular.

Assim, o fator tempo ainda se mantêm como determinante, isto é, a exigência de comprovação de quanto tempo foi gasto com aquela aula, aparentemente, é a comprovação de que ela aconteceu, de que a professora esteve este tempo com o aluno, caindo, de certa forma, no mesmo círculo vicioso do tempo cronometrado da escola, sem levar em consideração o processo. Neste sentido, a citação de Lavanda evidencia o processo da aula:

Pesquisadora: Você consegue especificar diferenças entre o trabalho na
escola regular e aqui no hospital?
Lavanda: Ah, no sentido de conteúdo, de ensino? Nós trabalhamos aqui
muito mais próximas do aluno, você consegue criar um vínculo mais rápido e
o resultado é melhor. Às vezes, em dois dias como no caso da [aluna] ou da
[aluna]. A [nome], em dois dias ela começou a ler, ela não está lendo
fluentemente, ela está descobrindo que pode ler, talvez na escola ela fosse
levar duas, três semanas. Não por culpa da escola, da professora, mas, tem
trinta, tem vinte em sala, então a dificuldade é maior. O legal, que eu percebo
muito, é que a mãe, quando a mãe tem vontade, tem interesse, ela também
faz isso. A mãe da [aluna] falou que levou um livro e fez o esquema da
caneta, do lápis e a [aluna] leu meio livro ontem à noite. Poxa vida, essa
ligação que a gente tem com eles e, às vezes, quando a gente consegue
trazer o pai e a mãe junto, faz toda a diferença na vida deles, porque o que
eles aprendem aqui eles vão levar, ela não vai desaprender a ler (LAVANDA.
Entrevista concedida em 20/09/2016, parágrafo 3823).

Sendo assim, fica expresso que tempo de aula não representa aprendizado.

Este é representado pela qualidade da troca, desejo de aprender, curiosidade, retorno do interesse. Se a escola regular - forma escolar, indica um caminho, é apenas isto a ser incorporado, tanto pela equipe da classe hospitalar, quanto pela escola regular, o que importa é o resultado positivo do percurso.

Pesquisadora: Você conseguiria identificar pontos negativos ou que dificultem o seu trabalho no programa?

Bromélia: A incompreensão das equipes que trabalham com saúde. Isso é um ponto que eu acho negativo. Porque às vezes os familiares que ainda não entendem o que é o serviço do SAREH, não conhecem. E outro, as escolas, 


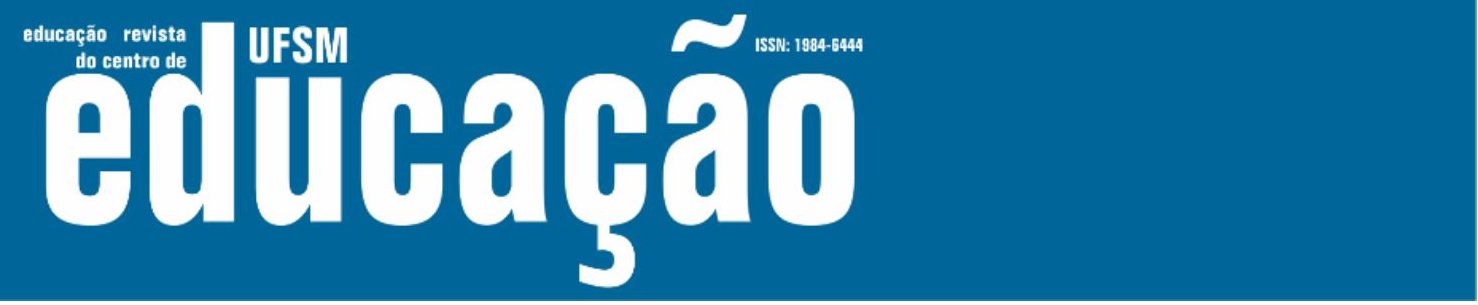

ISSN: 1984-6444 | http://dx.doi.org/10.5902/1984644440241

em geral, que não têm conhecimento da amplitude do trabalho do SAREH, então, a gente faz um trabalho aqui, e eles, às vezes, nem sabem como funciona isso. Deixa a desejar essa interlocução entre escola e SAREH. Deveria ter mais divulgação para a rede [escolar], falar do que se trata, o que é o SAREH, como é que atua, como é que funciona. Se você hoje for nas escolas, $80 \%$ diretores, professores, não sabem o que é SAREH. Saber que existe, alguns sabem. E 50\% têm conhecimento do programa, mas não sabem como funciona. Outros tantos, não sabem que existe.

(Obs.: os dados que Bromélia cita são fictícios, servem para exemplificar o desconhecimento a respeito do serviço).

Pesquisadora: Isso dificulta o trabalho?

Bromélia: Isso dificulta muito, porque o aluno vem de lá, a gente pede o que ele está vendo, qual é o conteúdo, para a escola mandar, a escola não sabe como funciona, o que vai mandar? Os professores mandam conteúdo [atividades] que eles estão dando para a turma no regular, e querem que a gente aplique isso para o aluno aqui. Não tem como.

Pesquisadora: E quando acontece isso, quando eles mandam essa atividade igual, como que vocês fazem aqui?

Bromélia: A gente flexibiliza, adapta. Tem que fazer a flexibilização daquilo, adaptar à realidade do aluno, e pegar o suprassumo do suprassumo. 0 essencial, para ele entender que, é aquele conteúdo que está sendo aplicado na turma dele, quando ele chegar, ele ter noção.

Pesquisadora: E quando vocês fazem isso, a escola, a escola aceita isso bem?

Bromélia: Aceita. Nesse ponto elas estão aceitando. Até por desconhecimento, elas não vão contra, têm medo da Secretaria (risos). Essa é a verdade. O SAREH [as vezes] representa a Secretaria. É o núcleo, é a Secretaria. Então, "veio lá do SAREH, veio da Secretaria, vai ser assim, acabou" acatam, sem ter domínio. Pelo fato de achar que é de uma instância superior. Algumas, por desconhecimento. E as que têm conhecimento, porque conhecem, sabem o que é o programa, que é assim que funciona. $E$ outras, por desconhecimento, não vão contra (BROMÉLIA. Entrevista concedida em 09/11/2016, parágrafo 300).

Com base no que diz Deleuze (1992), as subjetividades desses tempos de ação escolar hospitalar que perpassam pelas relações são afetadas. A subjetividade no nível individual, recebe uma onda de força da solidez institucional, que tenta penetrar na relação face a face. Isso quer dizer que um fluxo deste tipo passa pelas professoras, e existe uma margem de escolha, que marca até onde elas podem ir, porque as regras são (im)postas subjetivamente, paralelamente, muitas vezes, alheias às normatizações, nas ações do papel institucional que é assumido por alguns profissionais da educação nos hospitais, e a escolha da professora é assumir o risco que fica no limite: dar um passo a mais.

Quem assume este lugar (do/no institucional) impõe controle numa circunstância paradoxal, que exige por um lado, a solidez, por outro e ao mesmo 


\section{Uism \\ ISSN: 1984-6444

ISSN: 1984-6444 | http://dx.doi.org/10.5902/1984644440241

tempo, a flexibilização, desde que, esta última, permaneça apenas entre a professora e o aluno-paciente. Deste modo, a formação do lugar também é desterritorializada, e lugar retoma a essência do território, onde, "parece que não adianta ser um nômade com relação aos espaços disciplinares, visto que a própria sociedade criou um dispositivo nômade que captura a subjetividade em movimento" (CARDOSO JUNIOR, 2012, p. 606). A ação de mudança da prática recai sempre na busca de contornos, linhas de fuga ${ }^{1}$ e de ruptura para realizar o acontecimento classe hospitalar dentro da única referência que é flexibilidade do próprio tempo-espaço (DELEUZE e GUATTARI, 1992).

Um ponto de fuga das professoras está na percepção e na sensação da valorização do seu trabalho, sentem-se satisfeitas, conforme se lê nas entrevistas. Outro está na consolidação de ser efetivamente professora, ver in loco o bom resultado, dentro do simbolismo desta profissão. Enquanto na sala de aula ela é coisificada tanto quanto o aluno, no hospital, torna-se tão sujeito quanto o alunopaciente. Ela constrói sua realidade e experiência professoral, no tempo vivido e valorizado pelos sujeitos desse movimento - o aluno-paciente, os acompanhantes, e as equipes da saúde, independente do fluxo sólido institucional que atravessa essas relações. Como mostra Cardoso Júnior,

É que, em nosso tempo, não basta uma vontade de contestação; não é suficiente ser um outsider que se mete nas brechas dos espaços disciplinares para encarnar um nômade [...]. Toda vez que um fluxo de subjetivação (processo formador de subjetividades) passa por nós e experimentamos com ele a liberdade de nos tornarmos outros, automaticamente, estamos em uma rede de controle (CARDOSO JUNIOR, 2012, p. 607).

Fica claro que, o nômade ao qual se refere, não é necessariamente, um sujeito que sempre se movimenta, ao contrário, ele pode inclusive permanecer imóvel, porém, sempre escapa dos códigos comuns, das condutas impostas, ele revoluciona (DELEUZE e GUATTARI, 2008).

\footnotetext{
${ }^{1}$ Linha de fuga: "o que define uma situação é uma certa distribuição dos possíveis, o recorte espaço-temporal da existência (papéis, funções, atividades, desejos, gostos, tipos de alegrias e dores etc.). Não se trata tanto de ritual - de repetição morna, de alternância demasiado regulada, de exiguidade excessiva do campo de opções -, mas da própria forma, dicotômica, da possibilidade: ou isso ou aquilo, disjunções exclusivas de todas as ordens" (François ZOURABICHVILI, 2004 p. 29).
} 


\section{Tusm \\ ISSN: 1984-6444

ISSN: 1984-6444 | http://dx.doi.org/10.5902/1984644440241

\section{Considerações finais}

A pesquisa permitiu observar a naturalização do sentido (das coisas), mostrou, pela voz dos sujeitos, os elementos que caracterizam as ações, na tentativa de desnaturalizar certos modos de ver, mostrando como e porque as coisas acontecem, como acontecem e porque os objetos ou sujeitos são vistos de certo modo, sendo que existem outras formas de percebê-los.

Não há espaço, em uma sociedade hierarquizada, que não seja hierarquizado e que não exprima as hierarquias e as distâncias sociais, sob uma forma (mais ou menos) deformada e, sobretudo, dissimulada pelo efeito de naturalização que a inscrição durável das realidades sociais no mundo natural acarreta: diferenças produzidas pela lógica histórica podem, assim, parecer surgidas da natureza das coisas (basta pensar na ideia de "fronteira natural"), (BOURDIEU, 2008, p. 160).

Por isso, nesta pesquisa, algumas características encontradas foram a complexidade, a volatilidade e a instabilidade, já que tratamos sobre pessoas e suas ações nos lugares. Além do aspecto humano inserido na espacialidade, percebemos que a dimensão política desses processos é muito complexa e abre possibilidades que podem ser analisadas à luz das ações institucionais ou coletivas. Isso significa, muitas vezes, defrontar-se com elementos historicamente amalgamados nas relações e nas práticas que são quase impossíveis de contornar. Nesse sentido, encontramos nas entrevistas, as linhas de fuga, as possibilidades que as professoras encontraram para escapar de certos hábitos e recriar.

Outro fator de análise está atrelado ao tempo, como diferenças corporais e diferenças ambientais: é o tempo e modo de ensinar e aprender, que é individual. $\mathrm{O}$ desejo de controlar a aula choca-se com o acaso, o inesperado, que rondam a prática. O tempo de estudar e aprender muda, na classe hospitalar leva menos tempo, fato incomum: se aprende, doente e ainda em tão pouco tempo? Processos difíceis de registrar no tempo do relógio, o único considerado pela burocracia, ainda assim, é preciso demonstrar a utilidade das aulas com dados objetivos. O tempo mostra que a pequena interação em tempo real significada representa mais ao estudante, tem mais valor que o tempo desintegrado da escola regular. 


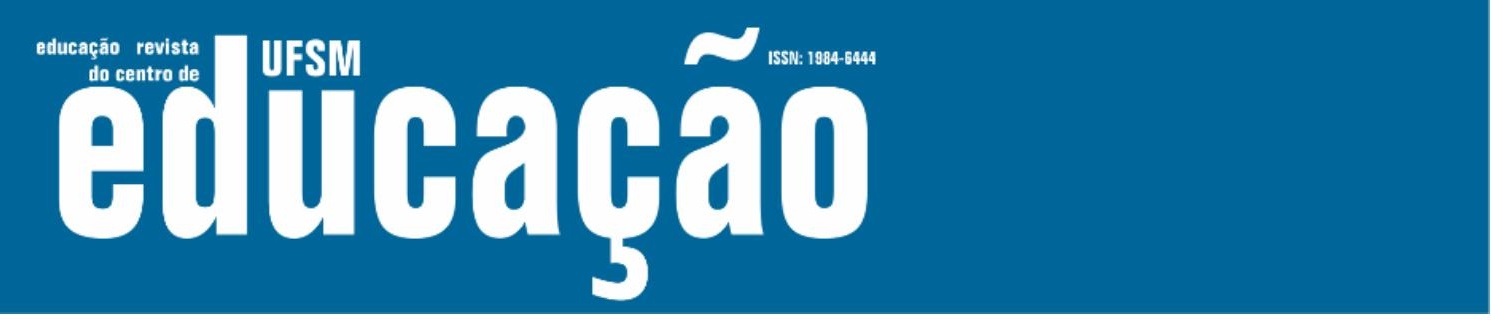

ISSN: 1984-6444 | http://dx.doi.org/10.5902/1984644440241

Tratando-se de uma situação de ensino que se realiza fora do território socialmente estabelecido (escola) com alunos em processo de doença, a questão do corpo é preponderante e foi preciso perceber e revelar as características culturais de cada um dos sujeitos para compreender as suas peculiaridades. A interação e a confiança permitem um processo de ensinar e aprender com base em experiências pessoais. As professoras relataram que a classe hospitalar é um lugar de encontros, de desenvolvimento pessoal, profissional e humano: conviver, aprender, adaptar-se, mudar, reorganizando os relacionamentos com pares e outros grupos - numa integração entre a saúde e educação. Possibilidades de fazer diferente diante da diferença, criar sobre o que parecia impossível, fazer acontecer aprendizagem em uma situação que não se espera nada além da cura ou da morte.

\section{Referências}

BOURDIEU, Pierre. A Miséria do mundo sob direção de Pierre Bourdieu; com contribuições de A. Accardo ...et. al. 17. ed.-Petrópolis, RJ: Vozes, 2008. Título original: La misere du monde. Vários tradutores. $752 \mathrm{p}$.

CARDOSO JUNIOR, Hélio Rebello. Por que ainda é importante pensar como um nômade em nosso tempo? Educação e Filosofia Uberlândia, v. 26, n. 52, p. 599-611, jul./dez.

2012.

Disponível

em: http://www.seer.ufu.br/index.php/EducacaoFilosofia/article/view/11582 Acesso em: 20 jan. 2017.

DELEUZE, Gilles. GUATTARI, Félix. O que é a filosofia? (trad. Bento Prado Jr. e Alberto Alonso Muñoz). Rio de Janeiro: Editora 34. 1992.

DELEUZE, Gilles; GUATTARI, Félix. Mil-Platôs: capitalismo e esquizofrenia. Vol. 1-5. RJ: Editora 34, 2008.

LIMA. A. M. L. Classe hospitalar: do território ao lugar em tempos e espaços educacionais. 2018. 254 p. Tese (Doutoramento em Ciências da Educação) Faculdade de Filosofia, Letras e Ciências Humanas. Departamento de PósGraduação em educação e Saúde na Infância e na Adolescência. São Paulo, Guarulhos. 2018.

VINCENT, Guy; LAHIRE, Bernard; THIN, Daniel. Sobre a história e a teoria da forma escolar. In: Educação em Revista, Belo Horizonte, n. 33, jun./2001. 


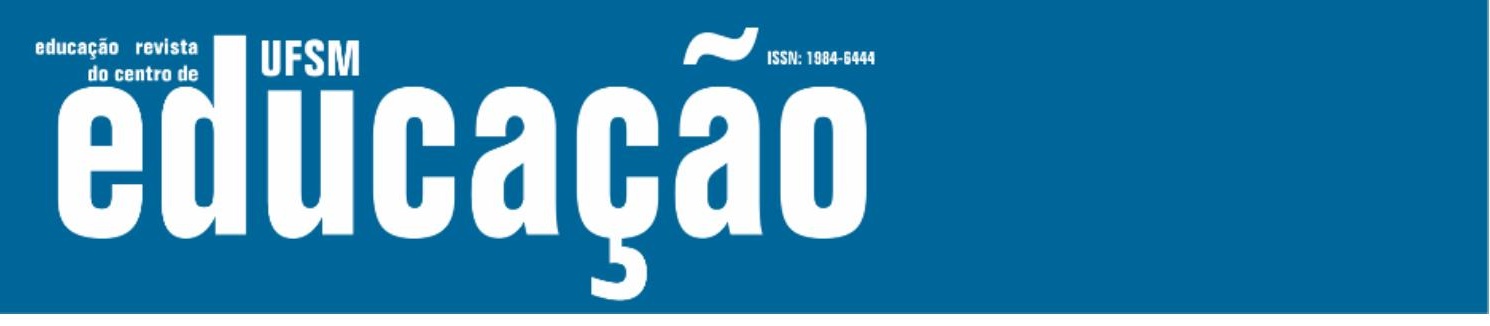

ISSN: 1984-6444 | http://dx.doi.org/10.5902/1984644440241

ZOURABICHVILLI, François. (2004). Vocabulário de Deleuze (A. Telles, trad.). Rio de Janeiro, RJ: Relume Dumará. Disponível em: http://escolanomade.org/wpcontent/downloads/deleuze-vocabulario-francois-zourabichvili.pdf. Acesso em: 05 nov. 2014.

\section{Correspondência}

Angélica Macedo Lozano Lima - Universidade Federal de São Paulo - Rua Sena Madureira, 1500. Vila Clementino, CEP 04021-001, São Paulo, São Paulo, Brasil.

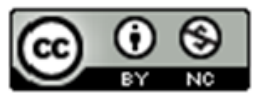

This work is licensed under a Creative Commons Attribution-NonCommercial 4.0 International (CC BY-NC 4.0)

\section{Notas}

\footnotetext{
${ }^{1}$ A pesquisa que aconteceu entre 2014 a 2018 contou com financiamento da CAPES

${ }^{2}$ Para preservar o anonimato dos sujeitos entrevistados, seus nomes foram substituídos por nomes de flores e suas áreas de atuação também foram ocultadas, portanto, não é possível nestes casos, determinar nem mesmo o gênero ou a função dos entrevistados, mas, sabe-se que são, ou professor (a) ou pedagogo (a), na grande maioria. É preciso ressaltar que as professoras e pedagogas estão no mesmo ambiente durante as aulas, quando a aula é na sala de aula no hospital (que é uma sala específica, cedida pelo hospital para o atendimento educacional). Pedagogas não estão presentes na classe hospitalar, (no leito) quando está apenas a professora e o aluno, salvo momentos em que a presença da pedagoga se faz necessária, para entregar algum documento, por exemplo. Sendo assim, é preciso compreender que à professora, cabe o papel de fazer todo o trabalho docente (ensino-aprendizagem, elaboração dos materiais didáticos e preparação e ministração das aulas), enquanto a pedagoga, tem por função organizar o espaço, os equipamentos e o trabalho docente, faz a mediação entre a escola, os responsáveis e o aluno, nos aspectos documentais, ou seja, são funções diferentes e que devem ser complementares. No Sareh, a pedagoga não tem o papel de ensinar, mas, de administrar o trabalho burocrático, como a documentação dos alunos, as fichas individuais, entre outros. A investigação passou pela aprovação do projeto pelo Comitê de Ética em Pesquisa (CEP) da Universidade Federal de São Paulo (UNIFESP). Deste modo, seguiram-se todas as normas da resolução 466/2012 do Conselho Nacional de Saúde (CNS). A lista de hospitais que ofertam este serviço pode ser encontrada em: http://www.gestaoescolar.diaadia.pr.gov.br/modules/conteudo/conteudo.php?conteudo=462.
}

${ }^{3}$ Além da formação profissional, outros fatores implicam na conduta pessoal, no texto, procurou-se destacar alguns fatores ligados com a educação, entre eles, a formação, que pode ser compreendida de modo geral ou apenas a formação acadêmica profissional, já que os modos e hábitos pessoais estão intimamente ligados aos aspectos culturais também, porém, preferimos limitar a discussão. Além disto, a formação acadêmica nas licenciaturas, geralmente é pouco interdisciplinar, com uma tendência de se fechar.

${ }^{4}$ O artigo 67 da Lei de Diretrizes e Bases da Educação (Lei 9.394/1996) reconhece o direito dos professores a um período reservado a estudos, planejamento e avaliação. Duas professoras apontaram que, de acordo com o hospital que trabalham (ou trabalharam), a hora atividade não é cumprida ou não é realizada de forma que possa contemplar as necessidades do serviço, aliado ao fato de que se diminuiu o tempo dessas horas por meio de instrução normativa, (DIÁRIO DE CAMPO, 2016). 